\title{
Tenofovir: A new option for the treatment of chronic hepatitis B
}

\author{
This article was published in the following Dove Press journal: \\ Virus Adaptation and Treatment \\ I September 2009 \\ Number of times this article has been viewed
}

\section{Walid S Ayoub \\ Division of Gastroenterology and Hepatology, Department of Medicine, Stanford University Medical Center, Stanford, CA, USA}

Correspondence: Walid S Ayoub 750 Welch Road, Suite 210, Palo Alto, CA 94304, USA

Tel +I 6504986084

Fax + I 6504985692

Email wayoub@stanford.edu
Abstract: Treatment of chronic hepatitis B (CHB) continues to evolve. Over the last decade, progressively lower levels of serum HBV DNA have been used as a threshold for treatment. A high degree of antiviral potency and a low rate of resistance are the two most important factors in the choice of an agent for therapy of CHB. Achieving rapid viral suppression is also a key factor in choosing the first line of therapy. Swift and potent viral suppression decreases the risk of hepatic decompensation, development of hepatocellular carcinoma and subsequent need for liver transplantation. Currently, entecavir and tenofovir are the most potent nucleoside and nucleotide analogs with the lowest rate of resistance in treatment-naïve patients. This review will evaluate the safety and efficacy of the use of tenofovir disoproxil fumarate, the newest agent, for the treatment of patients with CHB.

Keywords: tenofovir, TDF, chronic hepatitis B, resistance, safety

\section{Introduction}

Chronic hepatitis B virus (HBV) infection continues to be a major public health issue worldwide. More than 350 million people are infected with HBV worldwide. ${ }^{1}$ The magnitude of chronic hepatitis $\mathrm{B}$ (CHB) is underestimated, since epidemiological studies do not take into account the influx of immigrants from endemic areas or the prisoner population. $\mathrm{CHB}$ predisposes patients to premature death from cirrhosis, liver failure and/or hepatocellular carcinoma (HCC). ${ }^{1,2}$ Serum HBV DNA levels have also been directly linked to the risk of development of cirrhosis and HCC. ${ }^{2,3}$ Therefore, early detection and maximal suppression of serum HBV DNA may prevent disease progression to advanced stages. Current approved medications for hepatitis B e antigen (HBeAg)-positive and HBeAg-negative CHB in the United States (Tables 1 and 2) can be divided into immunomodulators (interferon $\alpha-2 b$, peginterferon $\alpha-2 a$ ), nucleoside analogs (lamivudine, telbivudine, and entecavir) and nucleotide analogs (adefovir dipivoxil [ADV] and tenofovir disoproxil fumarate [TDF]). Entecavir and tenofovir are the two oral antivirals shown to have the lowest risk for the development of antiviral drug resistance. ${ }^{4}$ Efficacy of oral antiviral medication has been traditionally measured by the ability of the drug to result in normalization of alanine aminotransferase (ALT), histological improvement and viral suppression. However, there is no clear evidence that the level of the ALT is directly correlated with the long term response to oral antiviral therapy.

Tenofovir is an acyclic nucleotide reverse transcriptase inhibitor, closely related to adefovir, which demonstrates activity against both human immunodeficiency virus 
Table I Responses to antiviral therapies in treatment-naïve patients with $\mathrm{HBeAg}$-negative chronic hepatitis $\mathrm{B}^{1,45^{*}}$

\begin{tabular}{|c|c|c|c|c|c|c|}
\hline & $\begin{array}{l}\text { Lamivudine } \\
\text { I00 mg daily } \\
\text { 48-52 weeks }\end{array}$ & $\begin{array}{l}\text { Entecavir } \\
0.5 \mathrm{mg} \text { daily } \\
48 \text { weeks }\end{array}$ & $\begin{array}{l}\text { Telbivudine } \\
600 \text { mg daily } \\
52 \text { weeks }\end{array}$ & $\begin{array}{l}\text { Adefovir } \\
10 \text { mg daily } \\
48 \text { weeks }\end{array}$ & $\begin{array}{l}\text { Tenofovir } \\
300 \text { mg daily } \\
48 \text { weeks }\end{array}$ & $\begin{array}{l}\text { Peg-IFn- } \alpha 2 a \\
48 \text { weeks }\end{array}$ \\
\hline Loss of serum HBV DNA & $60 \%-73 \%$ & $90 \%$ & $88 \%$ & $51 \%$ & $93 \%$ & $87 \%$ \\
\hline Normalization of ALT & $60 \%-79 \%$ & $78 \%$ & $74 \%$ & $72 \%$ & $77 \%$ & $49 \%$ \\
\hline Resistance & $70 \%$ at 4 years & $1.2 \%$ at 5 years & $11 \%$ at 2 years & $29 \%$ at 5 years & $0 \%$ at 2 years & $0 \%$ \\
\hline
\end{tabular}

Note: *Data do not reflect head to head comparison.

Abbreviations: ALT, alanine transferase; $H B V$, hepatitis $B$ virus.

(HIV) and HBV. It was first licensed for use in the treatment of HIV infection. Multiple retrospective analyses of subsets of patients coinfected with HIV and HBV treated primarily with tenofovir demonstrated the activity of tenofovir against HBV as well. ${ }^{5,6}$ In addition, a small case series of mostly lamivudine-resistant monoinfected HBV patients also documented the effectiveness of tenofovir in suppressing HBV, with 4-6 $\log _{10}$ reductions in serum HBV DNA..$^{7-9}$ Tenofovir received approval for the treatment of CHB based on phase III studies in 2008. ${ }^{10}$

\section{HBeAg-positive chronic hepatitis B}

The superiority of tenofovir to adefovir in HBeAg-positive CHB was recently demonstrated in a phase III study. Two hundred sixty-six treatment-naïve patients with $\mathrm{HBeAg-}$ positive CHB were randomly assigned to tenofovir (300 mg) or adefovir $(10 \mathrm{mg})$ at a 2:1 ratio. ${ }^{10,11}$ At 48 weeks of treatment, patients who received tenofovir had greater viral suppression of HBV DNA than those treated with adefovir, with $<400$ copies $/ \mathrm{mL}$ in $76 \%$ versus $13 \%$, ALT normalization in $68 \%$ versus $54 \%$, histological improvement in $67 \%$ versus $12 \%$, hepatitis B surface antigen ( $\mathrm{HBsAg}$ ) loss in $3.2 \%$ versus $0 \%$, and $\mathrm{HBeAg}$ seroconversion in $21 \%$ versus $18 \%$, respectively.

At 48 weeks, all of the patients in the adefovir group were switched to tenofovir (ADF-TDF group). Switching to tenofovir achieved more rapid viral suppression. Eighty-two percent of patients with detectable virus while receiving adefovir had undetectable HBV DNA ( $<400$ copies/mL, or $<69 \mathrm{IU} / \mathrm{mL}$ ) by week 96 . All patients who had undetectable HBV DNA at week 48 continued to have viral suppression by week 96 . In addition, $6 \%$ of patients in the ADF-TDF group had HBsAg loss by week $96 .^{12}$ Patients who lost HBsAg had either genotype A or D, high HBV DNA levels (median $9.48 \log 10$ copies $/ \mathrm{mL}$ ), and elevated HBsAg levels (5.11 $\log 10 \mathrm{IU} / \mathrm{mL})$ prior to treatment. ${ }^{13}$ The benefits of tenofovir persisted at week 96 , achieving maximal viral suppression ( $89 \%$ on treatment analysis), $\mathrm{HBeAg}$ seroconversion (26\%) and HBsAg seroconversion (4\%). ${ }^{12}$ No resistance to tenofovir was reported after 96 weeks of TDF monotherapy. ${ }^{14}$

\section{HBeAg-negative chronic hepatitis B}

Tenofovir has also been found to be superior to adefovir in a recent randomized controlled trial of 375 patients with HBeAg-negative CHB that included lamivudine-experienced patients. ${ }^{10}$ More patients in the tenofovir arm achieved undetectable HBV DNA levels (93\% versus $63 \%$, respectively) at 48 weeks. Both tenofovir and adefovir groups had similar rates of ALT normalization (77\% versus $78 \%$ ) and histological improvement ( $72 \%$ versus $69 \%$ ), respectively at week 48 of therapy. Histological improvement was defined

Table 2 Responses to approved antiviral therapies in treatment-naïve patients with HBeAg-positive chronic hepatitis $B^{1,45^{*}}$

\begin{tabular}{|c|c|c|c|c|c|c|}
\hline & $\begin{array}{l}\text { Lamivudine } \\
\text { I00 mg daily } \\
\text { 48-52 weeks }\end{array}$ & $\begin{array}{l}\text { Entecavir } \\
0.5 \text { mg daily } \\
48 \text { weeks }\end{array}$ & $\begin{array}{l}\text { Telbivudine } \\
600 \text { mg daily } \\
52 \text { weeks }\end{array}$ & $\begin{array}{l}\text { Adefovir } \\
10 \text { mg daily } \\
48 \text { weeks }\end{array}$ & $\begin{array}{l}\text { Tenofovir } \\
300 \text { mg daily } \\
48 \text { weeks }\end{array}$ & $\begin{array}{l}\text { Peg-IFn- } \alpha 2 a \\
48 \text { weeks }\end{array}$ \\
\hline Loss of serum HBV DNA & $40 \%-44 \%$ & $67 \%$ & $60 \%$ & $21 \%$ & $76 \%$ & $25 \%$ \\
\hline Loss of $\mathrm{HBeAg}$ & $17 \%-32 \%$ & $22 \%$ & $22 \%$ & $24 \%$ & $22 \%$ & $30 \%$ \\
\hline $\mathrm{HBeAg}$ seroconversion & $16 \%-21 \%$ & $21 \%$ & $22 \%$ & $12 \%$ & $21 \%$ & $27 \%$ \\
\hline Normalization of ALT & $41 \%-75 \%$ & $68 \%$ & $77 \%$ & $48 \%$ & $68 \%$ & $39 \%$ \\
\hline HBsAg loss & $<1 \%$ & $2 \%$ & $<1 \%$ & $0 \%$ & $3 \%$ & $3 \%$ at week 72 \\
\hline Resistance & $69 \%$ at 5 years & $1.2 \%$ at 5 years & $25 \%$ at 2 years & NA & $0 \%$ at 2 years & $0 \%$ \\
\hline
\end{tabular}

Note: *Data do not reflect head to head comparison.

Abbreviations: ALT, alanine aminotransferase; $H B V$, hepatitis $B$ virus. 
as $\geq 2$-point reduction in Knodell necroinflammatory score without worsening of fibrosis. No patients lost HBsAg during the 48-week course of therapy.

After 48 weeks, adefovir patients were rolled over into the tenofovir arm (ADF-TDF). All patients who had undetectable serum HBV DNA at week 48 continued to have maximal viral suppression by week 96. Of the 35 ADFTDF patients with undetectable HBV DNA at week 48, 94\% (33/35) achieved continued HBV DNA suppression at week $72 .{ }^{15}$ In an intent-to-treat analysis, $89 \%$ of patients who were switched from adefovir to tenofovir at week 48 had undetectable HBV DNA by week $96 .{ }^{16}$

\section{Lamivudine- or adefovir-experienced patients}

Efficacy of tenofovir in suppressing lamivudine-resistant HBV was demonstrated in small observational studies in lamivudine-resistant patients who had incomplete viral suppression after switching to adefovir. van Bommel and colleagues ${ }^{8}$ described a pool of 20 lamivudineresistant patients (18 patients with $\mathrm{HBeAg-positive}$ CHB) who were switched to tenofovir after poor virologic response after four to 28 months of adefovir therapy (HBV DNA $>4 \log 10$ copies $/ \mathrm{mL}$ ). None of the patients had evidence of adefovir resistance at the initiation of tenofovir therapy. Nineteen of the 20 patients achieved undetectable HBV DNA levels after a median duration of 3.5 months of treatment. The only patient with detectable HBV DNA was on a reduced TDF dose due to renal insufficiency.

More recent studies demonstrated the efficacy of tenofovir in nucleos $(\mathrm{t})$ ide analog-experienced patients. A European multicenter study evaluated the effect of tenofovir in mixed populations of $\mathrm{HBeAg}$-positive and $\mathrm{HBeAg}$-negative patients with prior exposure to nucleos(t)ides analogs. ${ }^{17}$ One hundred twenty-one treatment-experienced patients (16 lamivudine, nine adefovir, 72 sequential lamivudine and adefovir, 21 add-on combination of lamivudine and adefovir, two entecavir, and one sequential lamivudine and entecavir) were treated for one year with tenofovir. A one-year analysis of available data on 103 patients demonstrated that tenofovir therapy resulted in $85 \%$ with undetectable serum HBV DNA and $70 \%$ with normalization of ALT levels. No viral breakthrough (defined as HBV DNA $>1 \log 10$ from nadir) was observed. Patients with HBV DNA $<7 \log 10$ copies/mL at baseline were more likely to have undetectable HBV DNA after 52 weeks of tenofovir therapy. ${ }^{17}$

Tenofovir was also recently found to be equally effective in suppressing HBV DNA in lamivudine-naïve $(\mathrm{n}=350)$ as well as lamivudine-experienced $(n=49)$ patients in a subanalysis of tenofovir phase III trials. ${ }^{10,11}$ Ninety-two percent of lamivudine-naïve and $84 \%$ of lamivudineexperienced patients achieved undetectable virus at week 96 of tenofovir therapy based on an intention-to-treat analysis. ${ }^{18}$ No polymerase resistance to tenofovir was detected during the 96 weeks of therapy in either group.

Several other studies have demonstrated superiority of tenofovir to adefovir in reducing serum HBV DNA levels in lamivudine-experienced HBV-monoinfected patients or in patients coinfected with HIV. ${ }^{8,17,19,20}$ the superiority of tenofovir to adefovir may be related to the higher dose of tenofovir compared to adefovir (300 mg vs. $10 \mathrm{mg}$ ) in clinical practice. ${ }^{8}$ Tenofovir was able to continuously suppress HBV DNA for up to five years in lamivudine-experienced patients. ${ }^{21}$

Viral rebound was illustrated in a case series of 16 patients with undetectable levels of HBV DNA who were switched from tenofovir to adefovir. Adequate viral suppression was re-established when patients were switched back to tenofovir therapy in the absence of adefovir resistance. ${ }^{22}$ However, patients with adefovir resistance had suboptimal responses to tenofovir monotherapy, suggesting cross-resistance between adefovir and tenofovir. ${ }^{22}$ The patients with adefovir resistance and partial response to tenofovir were able to achieve optimal HBV DNA suppression once emtricitabine was added to therapy. ${ }^{22}$

Similar findings were also reported in an abstract by van Bommel and colleagues ${ }^{23} \mathrm{~A}$ recent retrospective analysis of a multicenter European study of using tenofovir monotherapy in 160 nuceleos $(\mathrm{t})$ ide-experienced patients revealed inferior viral suppression in the adefovir-resistant group compared to the lamivudine-experienced group (52\% versus $100 \%$, respectively). ${ }^{24}$ Tenofovir monotherapy was also compared to emtricitabine (FTC) plus tenofovir (TDF/FTC) in a recent trial that included treatment-naïve, lamivudine- and adefovir-experienced patients (13 with lamivudine resistance and 10 with adefovir resistance) who were partial responders to six months of adefovir therapy (HBV DNA $>400$ copies $/ \mathrm{mL}) .{ }^{25}$ Fiftythree and 52 patients were distributed blindly to the tenofovir and TDF/FTC arms, respectively. Patients were allowed to switch to open-label TDF/FTC if they had persistent HBV DNA $>400$ copies/mL after 24 weeks of therapy. Sixteen patients from tenofovir and nine patients from TDF/FTC groups were switched to the TDF/FTC arm due to persistent viremia. Based on an intention-to-treat analysis in which noncompleters and those who were switched were considered treatment failures, $65 \%$ of tenofovir and $77 \%$ of TDF/FTC patients achieved undetectable levels of viremia at week $72 .{ }^{25}$ 
Such clinical observations are in agreement with in vitro data documenting decreased tenofovir antiviral activity against adefovir-resistant HBV compared to wild-type HBV. Prior in vitro studies had shown decreased susceptibility of HBV isolates with rtN236T and tA181V to tenofovir (by 4-fold versus 3.2-fold values, respectively). ${ }^{26}$

A combination of entecavir and tenofovir is also highly effective in suppressing HBV-monoinfected patients with advanced liver fibrosis and complex viral resistance patterns or patients with partial antiviral responses to prior therapies. ${ }^{27}$ Fourteen out of 20 patients with a median HBV DNA of 600,000 copies/mL achieved undetectable HBV DNA after a median treatment of 10 months, with nine partial responders to prior therapies becoming HBV DNA-negative for the first time. However, no patients demonstrated loss of HBeAg or HBsAg. ${ }^{27}$

\section{Cost effectiveness, viral resistance, and safety}

The price of lamivudine is much lower than the rest of the nucleoside and nucleotide analogs. However, its use has been associated with increased cost due to the extra cost of managing complications associated with emergence of resistance. Although, the initial cost of currently recommended first line therapy (entecavir, tenofovir and pegylated interferon) is high, cost modeling favors the use of tenofovir or entecavir over the long term but not in the short term. ${ }^{28,29}$

Resistance to tenofovir has only been documented in HIV monoinfection and hepatitis B patients co-infected with HIV. The rtA194T polymerase confers resistance in vitro to tenofovir in presence of basal core promoter and precore mutations especially in HBeAg-negative CHB. ${ }^{30}$ However, no resistance to tenofovir has been reported in patients with $\mathrm{HBV}$ monoinfection in $\mathrm{HBeAg}$-positive or $\mathrm{HBeAg-negative}$ CHB after 96 weeks of therapy. ${ }^{18}$ However, a longer duration of follow-up is required to determine if resistance is demonstrated with prolonged treatment.

Tenofovir is primarily excreted by the kidneys by active glomerular filtration and active tubular secretion. Tenofovir has been showed to cause mitochondrial damage in the renal proximal tubule in HIV patients. ${ }^{31}$ The multidrug resistance protein, MRP4, has also been implicated in tenofovir nephrotoxicity in HIV patients. ${ }^{32}$ Co-administration of drugs eliminated by tubular secretion can lead to increase serum concentration of tenofovir or the co-administered drug. The manufacturer recommends calculating creatinine clearance at initiation of therapy and adjusting the dose depending on creatinine clearance while on therapy. The dosing interval should be changed with any change in creatinine clearance (Table 3). Acute renal failures, proximal renal tubular dysfunction with and without Fanconi syndrome have been described in patients receiving tenofovir in combination with other drugs for HBV-HIV coinfection. ${ }^{32,33}$ Nephrotoxicity was reversible with early discontinuation of tenofovir. Patients presented with varying degrees of hypophosphatemia, glycosurea, proteinuria, increased creatinine level and decreased creatinine clearance. ${ }^{32}$ However, an ongoing trial of tenofovir in HBV-monoinfected patients has not found significant nephrotoxicity associated with tenofovir after 96 weeks of therapy. ${ }^{34}$ No patient had a decrease in creatinine clearance $<50 \mathrm{~mL} / \mathrm{min}$, a rise in creatinine of $0.5 \mathrm{mg} / \mathrm{dL}$, or graded serum creatinine abnormality. However, one patient suffered a serious adverse event with a rise in creatinine to $1.4 \mathrm{mg} / \mathrm{dL}$ with improvement to $1.2 \mathrm{mg} / \mathrm{dL}$ at week $96 .^{18,34}$ Two patients out of a cohort of 50 lamivudine-experienced patients were noted to have a rise in serum lipase in a subanalysis of the ongoing trial. ${ }^{18} \mathrm{~A}$ retrospective multicenter analysis also demonstrated that tenofovir is well tolerated in nucelos(t)ide-experienced patients and was not associated with a statistically significant decrease in creatinine clearance. However, individual changes in creatinine clearance were noted. ${ }^{35}$ Experts recommend serum creatinine and phosphorus monitoring in addition to urinalysis every three months during treatment with tenofovir particularly in patients with pre-existing kidney disease. ${ }^{36}$

The two phase III registration trials of tenofovir included 81 cirrhotic patients, and the efficacy and safety of tenofovir were not influenced by the presence of cirrhosis. None of the cirrhotic patients had a rise in creatinine of $0.5 \mathrm{mg} / \mathrm{dL}$, creatinine clearance $<50 \mathrm{~mL} / \mathrm{dL}$, or clinically evident hepatic decompensation after 96 weeks of therapy. ${ }^{37}$ A small pilot study addressed the safety and efficacy of entecavir combined with tenofovir in eight HBV treatment-naïve cirrhotic patients. ${ }^{38}$ Five of the eight patients

Table 3 Tenofovir dose adjustment according to creatinine clearance Creatinine clearance Tenofovir dose adjustment (mL/min)

\begin{tabular}{ll}
\hline 50 or greater & $300 \mathrm{mg}$ every 24 hours \\
$30-49$ & $300 \mathrm{mg}$ every 48 hours \\
10-29 & $300 \mathrm{mg}$ every 72 to 96 hours \\
Less than 10 not receiving & No recommendation available \\
hemodialysis & 300 mg every seven days or after a total \\
Hemodialysis & $\begin{array}{l}\text { of approximately I2 hours of hemodialysis. } \\
\text { The dose is to be given after hemodialysis }\end{array}$ \\
\hline
\end{tabular}


showed undetectable HBV DNA serum levels after a median treatment of 4.87 months, with improvement of ChildTurcotte-Pugh score from a mean of 9.6 to 6.5 without associated adverse events.

Tenofovir has been linked to a mild and short-lived decrease in bone density. Cases of osteomalacia and reduced bone density have been reported in HIV patients on long term tenofovir therapy. The decrease in bone mineral density was nonprogressive and not associated with symptoms during the first 48 weeks of therapy. ${ }^{36,39}$ However, no bone fracture linked to tenofovir use has been reported in HBV-monoinfected patients treated with tenofovir after 96 weeks. ${ }^{34}$

Tenofovir crosses the placenta and has been labeled by the US Food and Drug Administration as a pregnancy category B medication. The Antiretroviral Pregnancy Registry is a prospective international registry that collects voluntary reports of major teratogenic effects associated with antiretrovirals and HBV drugs administered during pregnancy. A recent review of the this registry from 1989 until July 31, 2008 revealed no increase in risk of birth defects in infants born to women treated with tenofovir when compared to the general population. ${ }^{40}$

\section{Conclusion}

The ultimate goal in management of CHB is to develop an agent that will allow patients requiring continuous therapy to discontinue therapy without recurrence of the disease. Recent data suggests quantification of HBsAg titers as predictive of long-term HBsAg loss and response to treatment, and its relationship to a sustained response in patients without $\mathrm{HBV}$ viremia. ${ }^{41}$ Although, clearance of HBsAg and $\mathrm{HBeAg}$ is associated with good prognosis, it does not always correlate into a cure. Disease progression can still occur, especially in patients with cirrhosis and in patients where $\mathrm{HBeAg}$ seroconversion occurred with therapeutic intervention. ${ }^{1,42,43}$ The persistence of viremia despite clearance of HBsAg has been linked to a point mutation in the S-gene, which results in failure to detect HBsAg. ${ }^{44}$

Tenofovir appears to have a high genetic barrier to resistance and has demonstrated therapeutic superiority to lamivudine and adefovir. It achieves rapid HBV DNA suppression and is effective in suppressing lamivudineresistant virus. A combination of entecavir and tenofovir was also found to be highly effective in the treatment of patients with complex HBV viral resistance patterns in small observational studies. However, the demonstration of lamivudine cross-resistance with telbivudine and entecavir caution against the use of tenofovir monotherapy in adefovir-resistant patients. Long-term safety and viral resistance monitoring will determine whether tenofovir will stand the test of time in maintaining its efficacy and safety in the arsenal of HBV medications.

\section{Disclosure}

The author reports no conflicts of interest.

\section{References}

1. Lok AS, McMahon BJ. Chronic hepatitis B. Hepatology. 2007;45: 507-539.

2. Iloeje UH, Yang HI, Su J, Jen CL, You SL, Chen CJ. Predicting cirrhosis risk based on the level of circulating hepatitis B viral load. Gastroenterology. 2006;130:678-686.

3. Chen CJ, Yang HI, Su J, et al. Risk of hepatocellular carcinoma across a biological gradient of serum hepatitis B virus DNA level. JAMA. 2006;295:65-73.

4. Ayoub WS, Keeffe EB. Review article: current antiviral therapy of chronic hepatitis B. Aliment Pharmacol Ther. 2008;28:167-177.

5. Lacombe K, Gozlan J, Boelle PY, et al. Long-term hepatitis B virus dynamics in HIV-hepatitis B virus-co-infected patients treated with tenofovir disoproxil fumarate. AIDS. 2005;19:907-915.

6. Dore GJ, Cooper DA, Pozniak AL, et al. Efficacy of tenofovir disoproxil fumarate in antiretroviral therapy-naive and -experienced patients coinfected with HIV-1 and hepatitis B virus. J Infect Dis. 2004;189: $1185-1192$.

7. Schildgen O, Sirma H, Funk A, et al. Variant of hepatitis B virus with primary resistance to adefovir. $N$ Engl J Med. 2006;354:1807-1812.

8. van Bommel F, Zollner B, Sarrazin C, et al. Tenofovir for patients with lamivudine-resistant hepatitis B virus (HBV) infection and high HBV DNA level during adefovir therapy. Hepatology. 2006;44:318-325.

9. Kuo A, Dienstag JL, Chung RT. Tenofovir disoproxil fumarate for the treatment of lamivudine-resistant hepatitis B. Clin Gastroenterol Hepatol. 2004;2:266-272.

10. Marcellin P, Heathcote EJ, Buti M, et al. Tenofovir disoproxil fumarate versus adefovir dipivoxil for chronic hepatitis B. N Engl J Med. 2008; 359:2442-2455.

11. Heathcote EJ, Gane E, Man D, et al. A randomized, double blind, comparision of tenofovir df (TDF) versus Adefovir dipivoxil (ADV) for the treatment of $\mathrm{HBeAg}$ positive chronic hepatitis B (CHB): Study GS-US-174-0103. Hepatology. 2007;46:861A.

12. Heathcote EJ GE, deMan RA, Chan S, et al. Two year tenofovir disoproxil fumarate (TDF) treatment and adefovir dipivoxil (ADV) switch data in HBeAg-positive patients with chronic hepatitis B (Study 103), preliminary analysis. Program and abstracts of the 59th Annual Meeting of the American Association for the Study of Liver Diseases; October 31-November 4, 2008; San Francisco, CA. Abstract 158. Hepatology. 2008;48:376A.

13. Heathcote EJ, Germanidis G, Dusheiko G, et al. Characteristics of HBeAg-positive patients with HBsAg loss/seroconversion following treatment with tenofovir disoproxil fumarate (TDF). J Hepatol. 2009; 50:S330.

14. Heathcote J, George J, Gordon S, et al. Tenofovir disoproxil fumarate (TDF) for the treatment of HBeAg-positive chronic hepatitis B: week 72 TDF data and week 24 adefovir dipivoxil switch data (study 103). J Hepatol. 2008;48:S32.

15. Marcellin P, Jacobson I, Habersetzer F, et al. Tenofovir disoproxil fumarate (TDF) for the treatment of $\mathrm{HBeAg}$-negative chronic hepatitis B: week 72 TDF data and week 24 adefovir dipivoxil switch data (study 102). J Hepatol. 2008;48:S26.

16. Marcellin P, Buti M, Krastev Z, et al. Two year tenofovir disoproxil fumarate (TDF) treatment and adefovir dipivoxil (ADV) switch data in HBeAg-negative patients with chronic heapitis B (study 102), preliminary analysis. Hepatology. 2008;48:370A. 
17. van Bommel F, De Man R, Stein K, et al. A multicenter analysis of antiviral response after one year of tenofovir mono-therapy in $\mathrm{HBV}$-monoinfected patients with prior nucleos $(\mathrm{t})$ ide analog experience. J Hepatol. 2008;48:S32.

18. Manns M, Jeffers L, Dalekos T, et al. Safety and efficacy of 96 weeks or tenofovir disoproxil fumarate therapy in lamivudine experienced patients. J Hepatol. 2009;50:S335.

19. van Bommel F, Wunsche T, Mauss S, et al. Comparison of adefovir and tenofovir in the treatment of lamivudine-resistant hepatitis B virus infection. Hepatology. 2004;40:1421-1425.

20. van Bommel F, Berg T. Reactivation of viral replication after replacement of tenofovir by adefovir. Hepatology. 2005;42:239-240.

21. van Bommel F, Mauss S, Schurmann D, et al. No evidence of tenofovir resistance in patients with lamivudine-resistant $\mathrm{HBV}$ infection during long term treatment for up to 5 years. Hepatology. 2006;44:664A.

22. Tan J, Degertekin B, Wong SN, Husain M, Oberhelman K, Lok AS. Tenofovir monotherapy is effective in hepatitis B patients with antiviral treatment failure to adefovir in the absence of adefovir-resistant mutations. J Hepatol. 2008;48:391-398.

23. van Bommel F, Trojan J, Feucht HH, et al. Tenofovir shows limited efficacy in treatment of HBV infections resistant against adefovir. Hepatology. 2007;46:644A.

24. van Bommel F, De Man R, Reijnders J, et al. Effectiveness of tenofovir DF (TDF) monotherapy in patients with prior experience to nucleoside/ nucleotide analogues by different pattern of pre-existing mutations. J Hepatol. 2009;50:S337.

25. Berg T, Moller B, Trinh H, et al. Tenofovir Disoproxil fumarate (TDF) versus emtricitabine plus TDF (FTC/TDF) for treatment of chronic hepatitis $\mathrm{B}(\mathrm{CHB})$ in patients with persistent viral replication receiving adefovir dipivoxil. J Hepatol. 2009;50:S328.

26. Qi X, Xiong S, Yang H, Miller M, Delaney WE 4th. In vitro susceptibility of adefovir-associated hepatitis B virus polymerase mutations to other antiviral agents. Antivir Ther. 2007;12:355-362.

27. Lutgehetmann M, Schollmeyer J, Volz T, et al. Rescue therapy with combination of entecavir and tenofovir in patients with chronic HBV, advanced fibrosis and multiple previous failures is safe and highly efficient. J Hepatol. 2009;50:S335.

28. Deniz B, Buti M, Brosa M, et al. Cost-effectiveness simulation analysis of tenofovir disoproxil fumarate (tenofovir), lamivudine, adefovir dipivoxil (adefovir) and entecavir of HeAg negative (-) patients with chronic hepatitis-B (CHB) in Spain. J Hepatol. 2008;48:S209.

29. Deniz B, Everhard R. Cost-effectiveness simulation analysis of tenofovir disoproxil fumarate in $\mathrm{HBeAg}$ negative (-) patients with chronic hepatitis-B (CHB) in Italy and France. J Hepatol. 2008;48:S209.

30. Amini-Bavil-Olyaee S, Herbers U, Sheldon J, Luedde T, Trautwein C, Tacke F. The rtA194T polymerase mutation impacts viral replication and susceptibility to tenofovir in hepatitis B e antigen-positive and hepatitis B e antigen-negative hepatitis B virus strains. Hepatology. 2009;49:1158-1165.
31. Kohler JJ, Hosseini SH, Hoying-Brandt A, et al. Tenofovir renal toxicity targets mitochondria of renal proximal tubules. Lab Invest. 2009;89:513-519.

32. Sax PE, Gallant JE, Klotman PE. Renal safety of tenofovir disoproxil fumarate. AIDS Read. 2007;17:90-2, 9-104, C3.

33. Verhelst D, Monge M, Meynard JL, et al. Fanconi syndrome and renal failure induced by tenofovir: a first case report. Am J Kidney Dis. 2002; 40:1331-1333.

34. Marcellin P, Heathcote E, Jacobson I, et al. Safety and tolerability of 96 weeks or tenofovir disoproxil fumarate (TDF) treatment in $\mathrm{HBeAg}$ negative and positive patients infected with chronic hepatitis $\mathrm{B}(\mathrm{CHB})$. J Hepatol. 2009;50:S336.

35. van Bommel F, De Man R, Ferenci P, et al. Evaluation of safety and tolerability of tenofovir DF (TDF) long term monotherapy in nucleos(t)ide analogue experienced patients with HBV monoinfection. $J$ Hepatol. 2009;50:S338.

36. Fontana RJ. Side effects of long-term oral antiviral therapy for hepatitis B. Hepatology. 2009;49:S185-S195.

37. Buti M, Hadziyannis S, Mathurin P, et al. Two years safety and efficacy of tenofovir disoproxil fumatate (TDF) in patients with $\mathrm{HBV}$-induced cirrhosis. J Hepatol. 2009;50:S10.

38. Amarapurkar D. Efficacy of combination of entecavir and tenofovir treatment in hepatitis B related decompensated chronic liver disease: pilot study. J Hepatol. 2009;50:S327.

39. Gallant JE, Staszewski S, Pozniak AL, et al. Efficacy and safety of tenofovir DF vs stavudine in combination therapy in antiretroviral-naive patients: a 3-year randomized trial. JAMA. 2004;292:191-201.

40. Brown RS, Buti M, Goodwin D, Zhang S, Fagan E. Hepatitis B virus (HBV) drugs in pregnancy: Findings from the antiretroviral pregnancy registry. J Hepatol. 2009;50:S4.

41. Lau G, Marcellin P, Brunetto M, et al. HBsAg decline in patients treated with PEGASYS and its association with post-treatment response in HBeAg-positive chronic hepatitis B. Hepatol Int. 2009;3:106-107.

42. Singh NA, Reau N. Management of hepatitis B virus. J Antimicrob Chemother. 2008;62:224-228.

43. Lim SG, Oo A, Wasser S. Treatment-induced HbeAg seroconversion is a poor therapeutic endpoint. Hepatology. 2007;46:937A.

44. Sheldon J, Soriano V. Hepatitis B virus escape mutants induced by antiviral therapy. J Antimicrob Chemother. 2008;61:766-768.

45. Keeffe EB, Dieterich DT, Han SH, et al. A treatment algorithm for the management of chronic hepatitis B virus infection in the United States: 2008 update. Clin Gastroenterol Hepatol. 2008;6:1315-1341; quiz 286.
Virus Adaptation and Treatment

\section{Publish your work in this journal}

Virus Adaptation and Treatment is an international, peer-reviewed open access journal focusing on the study of virology, viral adaptation and the development and use of antiviral drugs and vaccines to achieve improved outcomes in infection control and treatment. The journal welcomes original research, basic science, clinical \& epidemiological

\section{Dovepress}

studies, reviews \& evaluations, expert opinion and commentary, case reports and extended reports. The manuscript management system is completely online and includes a very quick and fair peer-review system, which is all easy to use. Visit http://www.dovepress.com/ testimonials.php to read real quotes from published authors. 